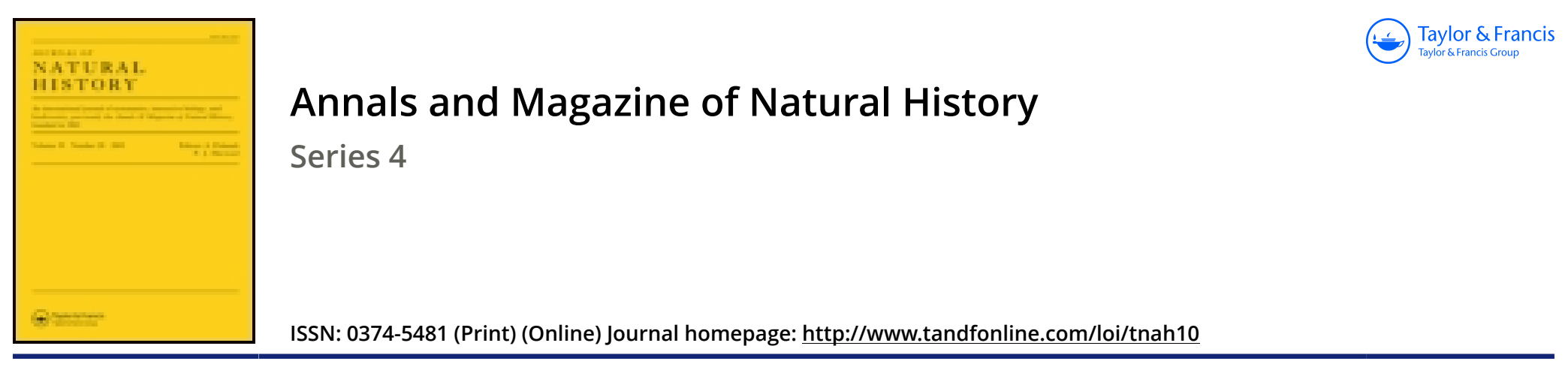

\title{
On a new organ of innervation, and on the origin of the nerves of special sensibility in the aquatic pulmonate Gasteropoda
}

\section{Lacaze-Duthiers}

To cite this article: M. Lacaze-Duthiers (1871) On a new organ of innervation, and on the origin of the nerves of special sensibility in the aquatic pulmonate Gasteropoda, Annals and Magazine of Natural History, 8:45, 217-219, DOI: 10.1080/00222937108696473

To link to this article: http://dx.doi.org/10.1080/00222937108696473

Published online: 16 Oct 2009.

Submit your article to this journal $\pi$

Џll Article views: 3

Q View related articles $\sqsubset$ 
be no longer present even in the embryos, then we shall be able to affirm that Nerophis is a good genus, because it will be quite distinct from Syngnathus. At present we cannot quite say that, as is proved by the uncertainty which prevails in the classification of certain speciez : thus, for example, Kaup places the Nerophes with rudimentary tail in the genus Nerophis, while Rafinesque and Bonaparte refer them to the genus Syngnathus.

"In the same manner the tertiary Calamostoma, in losing the caudal fin, gave rise to the existing Hippocampus, in which the caudal fin is only present in the embryo.

"It is extremely probable that the caudal fin, before disappearing from the adults, passes through the rudimentary state, as is the case in the species of Nerophis cited above. No Hippocampus is yet known presenting this degree of conformation; but one may entertain the expectation of discovering, either in the present seas or in the posteocene formations, Hippocampi possessing in the adult condition a rudimentary caudal.

"With fishes the caudal is a powerful organ of locomotion. In this respect Hippocampus is an exception, in that it effects its movements principally by means of the dorsal. To it a caudal would be almost useless ; and if that fin existed in the Calamostomes, perhaps the reason was that it was inherited from other fishes. In the Hip. pocamp $i$ it has been subjected to that law which condemns useless organs first to become rudimentary and then atrophied in the adults, and at last to disappear even in the embryo. The existing Hippocampi are found precisely in the second of these three phases."

The paper of $\mathrm{M}$. Canestrini concludes with a descriptive and analytical catalogue of the Lophobranchs of the Adriatic, comprising 12 species, distributed into 4 genera :-Hippocampus, 2 species; $\mathrm{Si}_{\text {- }}$ phonostomus, 2 ; Syngnathus, 6 , of which one (S.tonionotus) is new ; and Nerophis, 2. He rectifies numerous errors of synonymy committed by various authors, in particular by Bonaparte, whose 28 species of Lophobranchs ought to be reduced to 19.-Bibliotheque Universelle, Archives des Sciences Physiques et Naturelles, July 15 , 1871, pp. 355-358.

On a new Organ of Innervation, and on the Origin of the Nerves of Special Sensibility in the Aquatic Pulmonate Gasteropoda. By M. Lacaze-Duthrers.

In a former memoir I made known to the Academy a constant and important relation which exists between the organ of hearing and the posterior nervous centres of the Gasteropoda. Now, by the investigation of nervous centres by means of histological preparations intended to allow the nerves to be traced to their true and real origins, I have been led to the knowledge of new facts of great value for the knowledge of the relations and morphological comparisons.

I believe that no one has yet indicated the existence in the subAnn. \& Mag. N. Hist. Ser. 4. Vol. viii. 
œsophageal or posterior centres of the Gasteropoda in general, and of the aquatic Pulmonata in particular, of regions, lobes, or lobules having a peculiar structure, constant connexions, and of course distinct and precise physiological attributes.

The anterior centre of the cesophageal collar is destined to innervate the foot-that is to say, the immediate organ of movement, a motor organ which nevertheless is endowed with great sensibility. Now minute anatomy shows clearly in Paludina (a species of another group) that a thick cord descends from the posterior or cerebroid centre, attaches itself to the connective uniting the brain and the pedal ganglion, and gives origin to the nerve destined for the superior and eminently sensitive portion of the skin of the foot. Is it possible, after this observation, to refuse to recognize that the anterior ganglia are evidently in relation to motivity, and that the posterior centres are more particularly connected with sensibility? and, lastly, that these latter send forth to the other ganglia the fibres destined to give them sensibility?

From these facts we see how incomplete, from a physiological point of view, was the knowledge that we possessed with regard to the centres of innervation, and how important it was, by minute analysis, to arrive at the distinction of the special secondary parts in these centres.

This remark acquires still more interest when we ascertain, as I have done, that the more the nerves are destined for the perception of delicate and subtle impressions (in a word, the more they are sensitive and specialized), the more also are their origins placed upon the posterior face of the subcesophageal cerebroid centre.

It is not sufficient therefore to indicate in a general way what are the nerves that spring from a ganglion; it is also necessary to seek the points where, relatively and absolutely, the real origins occur. This is so true that cutaneous branches have been described as issuing from the optic nerve, which itself, in some cases, seems to spring from the nerve of the tentacle. This fact, which is difficult to admit $a$ priori (since nothing analogous is met with in the higher animals, the nervous system of which is so well known), is not proved by minute histological researehes. On the contrary, on separating, by histological processes and reactions, the bundles of fibres simply laid together and approximated under the same general neurilemma, we may ascend, in Physa, Planorbis, Lymnaca, \&c., to the real, precise, constant, and always distinct origin of the three nerves of special sensibility, the olfactive, acoustic, and optic nerves, and thus prove that this origin is always met with a little laterally upon the posterior face of the subcesophageal centre, round a small, prominent, hemispherical lobule, which merits the name of the lobule of special sensibility.

By indicating with precision the isolation and the distinct startingpoints of the nervous cords going to the three principal organs of the senses, $I$ bring a new proof in support of the general idea that, in the lower animals, in the nervous centres hitherto regarded as simple and homogeneous, there exist secondary parts which it is necessary 
to distinguish, since they have distinctly characterized relations and attributions.

The determination of the homologous parts of the different ganglia has led to the recognition of a new arrangement equally curious and unexpected, which will, I hope, interest physiologists.

It is well known that in the neighbourhood of the external orifice of respiration there is to be found, at the extremity of a large pallial nerve, a ganglion of moderate size, to which one was tempted to give the name of respiratory ganglion, in consequence of the functions which its position caused to be ascribed to it. Now, by subjecting this ganglion to microscopic observation, both directly and after chemico-histologieal preparation (in a word, by analyzing it), we find that it is formed of an accumulation of nervous corpuseles, almost all unipolar, in the midst of which is immersed an actual cæcal process of the skin. This arrangement shows that here the outer limits of the body, by a sort of invagination, become approximated as closely as possible to a nervous centre and to the deep-seated elements characteristic of the centres.

Thus, from the study of the minute structure of the nervous centres of the aquatic pulmonate Gasteropoda we may deduce:-

1. That in these animals, as in higher creatures, there exist regions or lobes the histological constitution and the connexions of which establish for them distinct, special, and localized attributions.

2. That the nerves of special sensibility originate from the posterior part, whilst the nerves of motion have their origin upon the most anterior ganglion.

3. That we must recognize in the supposed respiratory ganglion not a nervous centre or true ganglion, but a new special organ produced by the invagination of the skin in the midst of a mass of ganglionic corpuscles.-Comptes Rendus, July 17, 1871, tome lxxiii. p. 161.

\section{Further Observations on the Development of the Crayfish. By S. Chantran.}

My recent experiments have confirmed the facts noted by me last year*, especially with regard to the period of the life of the young crayfish beneath the abdomen of the mother. I have observed that not only do they feed upon the pellicle of the eggs and on the carapace shed in their first moult, but the stronger ones eat those individuals whose development is rendered difficult by their agglomeration and which cannot moult. The facilitation of this moult is probably one of the causes of the mother constantly agitating her false legs during the two or three days preceding exclusion; to these the young crayfish are suspended. Those which, in moulting, break their limbs, are also devoured by their companions. Thus the crayfish, when they are ten days old, eat each other; and this is the case also

* See Ann. \& Mag. N. H. ser. 4. vol. vi. p. 265. 